\title{
El viento y la covada. Mitos y ritos de las Baleares
}

El nacimiento y la muerte, primero y último acto, son sin duda los pasos más importantes en la vida humana. Pero el nacimiento biológico no es suficiente. Para conseguir un ser humano será necesario llevar a cabo rituales pautados que servirán para ir formando las esencias del nuevo ser social: alguien con alma, o sea, con facultades humanas y, por lo tanto, simbólicas.

Entre la naturaleza y la cultura, entre lo biológico y lo social, aparecen los elementos simbólicos, los mitos, las construcciones jurídicas y científicas que colocan al nuevo ser en la trama de su sociedad, con un sistema de valores y de creencias en el que se buscan criterios de "racionalidad". El tema de la racionalidad y el de la jerarquía, tanto en el papel procreativo como en el sociológico, puede analizarse a través de lo que el historiador Fernand Braudel denominaría la longue durée, al contar en el espacio mediterráneo con una cultura escrita de tres milenios y con una multiciplicidad de pueblos enraizados en los que se puede rastrear actualmente - $\mathrm{o}$ en un pasado inmediato- buena parte de los rituales y de las creencias antiguas.

\section{DEL MITO CÓSMICO AL MITO CIENTÍFICO}

Uno de los peores insultos que se le podía hacer a una mujer en las Baleares hasta los años setenta era llamarla "Xorca": estéril. Esta palabra catalana tiene su origen en el derecho de exorquía existente en el reino catalano-aragonés, por medio del cual los señores feudales heredaban las tierras de los colonos que no tenían descendencia. Mala cosa para aquel que quiere perpetuar su nombre o transmitir una propiedad.

Hasta hace muy poco, el hombre nunca era culpable de la esterilidad, que se imputaba siempre a la mujer: tierra estéril, puesto que el esperma era, por definición, fértil. Esta fatuidad, sin embargo, no siempre ha sido vista de igual manera; en épocas mucho más remotas, no estaba muy claro el papel fecundante del padre, tal como en algunas culturas primitivas han podido demostrar los antropólogos ${ }^{1}$. Y también por lo que

1 Entre los más conocidos, los trabajos que realizó Malinowski en las islas Trobriand. 
podemos discernir a través de ciertos mitos antiguos que los griegos difícilmente se explicaban, y a los que daban interpretaciones peregrinas, a través de las costumbres de otros pueblos que calificaron de no civilizadas porque se insertaban mal en su cultura patriarcal.

Uno de los mitos más considerables de la Hispania prerromana era que las yeguas astúricas y lusitanas quedaban preñadas por el viento (Céfiro). Esto fue recogido por autores clásicos como Plinio, Varrón, Justino y Silio Itálico, entre otros. Algunas de las versiones hacen aparecer las facultades fecundantes del viento en un monte sagrado. El poeta y clasicista Robert Graves $^{2}$ apunta que el filósofo Ptolomeo atribuye sólo al planeta Júpiter, que gobernaba el Norte, "vientos fecundos", y Bóreas era uno de los títulos de Zeus. En una nota comenta "una teoría primitiva de que los niños eran reencarnaciones de los antepasados difuntos, que se introducían en las matrices de las mujeres como súbitas ráfagas de viento, subsistía en el culto erótico de la diosa Yegua, y la autoridad de Homero ${ }^{3}$ pesaba lo suficiente como para que los romanos cultos siguieran creyendo, con Plinio -en la Historia Natural (IV, VIII)—, que las yeguas hispánicas pudieran concebir moviendo sus cuartos traseros al viento".

Según Columela ${ }^{4} \mathrm{y}$ Virgilio ${ }^{5}$, las yeguas tienen el celo en primavera, o sea, cuando despiertan los campos. Según este último: "En Lusitania, en los alrededores de Lisboa y del Tajo, las yeguas se ponen del costado del viento favonio, aspiran su aliento fecundante y quedan preñadas, y los potros que nacen son extremadamente rápidos". Y Julio Solino reasimila el mito, pues afirma que una vez fecundadas por el viento, las yeguas lusitanas se aparean después con los caballos. Aristóteles ${ }^{6}$ también recuerda "que se dice que las yeguas son fecundadas por el viento en el momento del celo" y que éste es en primavera, y extiende la teoría de este tipo de mito a algunas aves ${ }^{7}$.

2 Robert Graves, Los mitos griegos (Madrid: Alianza Editorial, 1981), vol. I.

3 HOMERo, Ilíada. Traducción catalana de Manuel Balasch (Barcelona: Selecta, 1971), $\mathrm{XX}$, pp. 219 y ss.

4 Columela (VI, 27), citado en Julio Caro Baroja, Los pueblos del Norte (San Sebastián: Txertoa, 1977).

5 VirgiLıO, Geòrgiques. Traducción catalana de Miquel Dolç (Barcelona: Fundació Bernat Metge, 1982), III, versos 266-276.

6 ARISTÓteles. Història dels animals. Traducción catalana de Juli Pallí (Barcelona: Fundació Bernat Metge, 1996).

7 Plutarco expresa, igualmente, que el viento puede fecundar a los pájaros antes de la época de la puesta. Plutarco, Propos de table. Traducción de François Fuhrmann et al. (Paris: Les Belles Lettres, 1972-1996), VIII, art. I, 3. 
En otro orden de cosas, Aristóteles ${ }^{8}$ comenta que las hembras más ardientes entre los animales son las yeguas y que de aquí viene aplicar el nombre de este animal a la mujer que usa sin mesura los placeres del amor.

Veamos algunos elementos que forman parte de la cultura griega, que tanto ha influido en nuestra cosmovisión docta y popular sobre el misterio de la vida y del universo. El concepto del pneuma desempeñó un papel importante desde los orígenes de la filosofía griega. Algunos presocráticos suponían la existencia de una substancia (el aire) que rodea y penetra el universo entero ${ }^{9}$; el aire rodea el universo del mismo modo que el alma ${ }^{10}$ (que es aire) mantiene la cohesión del organismo humano (y del animal).

Empédocles (circa 483/430 a. C.) consideraba que la substancia que llena el universo, al modo de un alma, es un pneuma, que aunque se traduce a veces por "espíritu", tiene aquí un sentido a la vez psíquico, orgánico y material. Estas ideas se pueden interpretar material y místicamente, los partidarios de esta última opción se apoyan en el hecho de que en la cultura griega de la época no había necesariamente conflicto entre lo filosófico (o científico) y lo religioso y, en general, entre lo racional y lo irracional.

Los estoicos - que tomaron prestado el concepto de pneuma de Anaxímenes- consideraban que el pneuma está compuesto de aire (substancia fría) y fuego (substancia cálida). Según los antiguos estoicos, el aire llena el cosmos y hace posible la cohesión de la materia por medio de su propiedad fundamental: la tensión. El pneuma es una substancia continua, cuyo movimiento no consiste en desplazamiento, sino en propagación de "estados" dentro de un "continuo". Muchas otras escuelas filosóficas griegas hicieron uso de este concepto, incluyendo las escuelas médicas hipocrática y siciliana. Según la Escuela de Sicilia, el pneuma es un soplo localizado en el cuerpo vivo y que penetra todo el organismo ${ }^{11}$.

En la iconografía cristiana son múltiples las escenas de creación por el soplo de Dios, que "insufla" vida. Mientras que el aliento humano, por

8 ARISTÓTELES, op. cit., VI, XVIII, 10.

9 H. Diels, Die Fragmente der Vorsukratiker (Berlín, 1934-1954). Citado por G.S. KIRK, y J. E. RAVEN, Los filósofos presocráticos (Madrid: Gredos, 1981). Cf. también Jonathan BARnes, Los presocráticos (Madrid: Cátedra, 1992).

10 Los términos usados en diversas culturas muestran cuán difundida se halla esta idea. Los vocablos nefesti (hebreo), nef (árabe), atman (sánscrito) y animus-anima (latín) - término éste último del cual proceden los nuestros románicos.

11 José Ferrater MORA, Diccionario de Filosofía (Madrid: Alianza Editorial, 1990). 
el contrario, es pesado y lleno de impurezas ${ }^{12}$. En época moderna, el término pneuma ha sido corrientemente empleado en el vocabulario teológico, sobre todo con referencia al Espíritu Santo. Éste, por ejemplo, en la tradición cristiana, se manifiesta siempre a través de un gran viento. Se ha hablado también de pneuma como espíritu y como alma, especialmente como objeto de la psicología racional ${ }^{13}$.

En la Grecia antigua, el poder fecundante de los vientos ocupará un lugar destacado en el pensamiento órfico. Los órficos, como los pitagóricos, desarrollaron la teoría del alma como soplo, hálito, en relación con la fecundación del viento (Himno órfico 81). Y esta idea aparece en relación con las creencias en los Tritopatores, espíritus de los Vientos, que son antepasados familiares y "Soplos fecundos" a la vez ${ }^{14}$. Algunos autores cristianos mencionarán todavía estas creencias: Eusebio afirma que entre los buitres no hay machos y las hembras conciben del pneuma. Creencia que servirá también para explicar el nacimiento virginal de Cristo ${ }^{15}$, que se mantendrá en la Edad Media y que llegará incluso hasta nuestros días a través de los cuentos y dichos populares.

El folklorista catalán Joan Amades ${ }^{16}$ todavía recoge en los años cuarenta historias populares en este sentido. Explica cómo el viento de tramuntana (el viento norte que, por lo tanto, coincide en el imaginario con Bóreas) que pasa por el Coll del Vent, cercano al barrio de Horta de la ciudad de Barcelona, fecunda a las barcelonesas. Por esta razón, asegura, ni por guerras, pestes u otras calamidades públicas ha cesado nunca la población de Barcelona. Parece que este viento fecundador entra en la ciudad por el viejo portal de Junqueras, sobre las dos de la tarde. Nuestras abuelas, dice Amades, recelaban de pasar por este lugar a dicha

12 Como será el caso extremo de las mujeres menstruantes, que con su aliento pueden corromper las matanzas y agrian la leche o el vino, aspectos que ya aparecen en Plinio y que se han manifestado en las zonas rurales hasta hoy mismo.

13 A lo largo de la evolución del pensamiento a través de la historia, el concepto de alma ha sufrido una serie de conceptualizaciones influidas, primero, por Platón y Aristóteles y, más tarde, por el Cristianismo. Jaspers, Scheler y Ortega y Gasset distinguen vida, alma y espíritu. Mientras que el alma es concebida como "sede" de los actos emotivos, los afectos, los sentimientos, etc., el espíritu es definido como "sede" de determinados aspectos racionales. El alma es inmanencia y el espíritu transcendencia (José FerRater MORA, op. cit. vol. I, p. 108).

14 Louis GERnET, Anthropologie de la Grèce antique (Paris: Flammarion, 1982) p. 22.

15 Lactancio, a fines del siglo III d. C. hace de este fenómeno una analogía de la fecundación de la Virgen por el Espíritu Santo.

16 Joan AMADEs, El folklore de Catalunya. Costums $i$ creences (Barcelona: Selecta, 1969). 
hora por miedo a quedarse grávidas. Pero por supuesto que los embriones de las catalanas serían hueros si los machos no los hiciesen madurar, tal como ocurre con las gallinas. Como bien afirmaba Solino en relación a las yeguas lusitanas, una vez grávidas por el viento, se apareaban con los caballos.

J. Bermejo Barrera (en relación al mito de la fecundación por el viento de las yeguas ibéricas) señala que no constituye una pieza aislada sino que forma parte de una teoría mitológica y filosófico-científica a la vez sobre la generación animal, vegetal y humana, tanto en sus aspectos físico-naturales como sociales (paternidad, maternidad, filiación). "Esta teoría se encuentra ampliamente desarrollada en los mitos y en el pensamiento griegos y cabe señalar en ella, entre otros muchos aspectos, la desigualdad de estatus de los seres machos y hembras en la teoría de la generación, destacando la importancia del varón o el macho en la fecundación y formación del embrión y disminuyendo el papel de la hembra ${ }^{17}$.

Considero que no es en este mito donde aparece la desigualdad, ya que se atribuye la fecundación de las yeguas a la obra y gracia del viento. Pero sí es cierto que aparecen estas características, o por lo menos lo intentan, en otros mitos y explicaciones generados por el pensamiento misógino de la Grecia clásica al que nos referiremos más adelante.

Luciano de Samosata, escritor griego nacido en Siria (125-192 d.C.), escribió en su Historia verdadera la narración de un viaje a la Luna, donde parodia algunos aspectos de la cultura griega, entre ellos algunos de sus mitos. Según Luciano ${ }^{18}$, los pueblos que habitan la Luna se componen sólo de hombres. Afirma:

Quiero ahora describir todo lo que durante mi estancia en la luna observé de extraño y raro. En primer lugar, sus habitantes no son engendrados por mujeres, sino por varones: en efecto, se casan con hombres y ni siquiera conocen el nombre de mujer. Hasta los veinticinco años cada uno es esposa, y después se convierte en marido; no llevan a sus hijos en el vientre, sino en las pantorrillas. Cuando el embrión está concebido, la pantorrilla engorda, y poco después la abren y sacan al niño muerto: lo colocan de cara al viento, con la boca abierta, y revive ${ }^{19}$.

17 J. Bermejo BARrera, Mitología y mitos de la España prerromana (Madrid: Akal, 1982), p. 99.

18 LuCiano DE SAmosata, Historia verdadera. Edición de Eulàlia Vintró (Barcelona: Labor, 1974), 1, p. 22 ss.

19 Isidoro de Sevilla (560-636) encuentra estas teorías desfasadas: "El nombre de alma (anima) es de origen pagano, y se llamó así a causa del aire. Y es que los hombres parecemos tener vida por el aire que respiramos, lo que es totalmente falso, ya que el alma es concebida mucho antes de que el ser humano pueda respirar el aire por su boca, pues en el vientre materno ya tiene vida. Por lo tanto el alma no 
Luciano hace un juego de palabras y comenta: "Me parece que de aquí procede el nombre de Gastroknemias (pantorrilla) entre los griegos, es decir "vientre de la pierna", porque es ésta la que concibe en vez del vientre". El coito en el pliegue de la rodilla preñaba su pantorrilla que, por lo tanto, haría las veces de útero. Cuando el niño iba a nacer se procedía a una cesárea de la rodilla. Esta historia grotesca no lo es tanto para los conocedores de los mitos griegos, ya que concentra en una sola historia los dos nacimientos de Dionysos: el de su extirpación antes de tiempo del vientre de su madre, Semelé, y el de su introducción en el muslo de Zeus, que le permite alumbrar a Dionysos por la pierna ${ }^{20}$.

$\mathrm{Al}$ étnologo y psicoanalista Georges Devereux ${ }^{21}$, el unisexismo de los lunares le recuerda a las amazonas, pueblo compuesto únicamente por mujeres. Sin embargo, en el tema que nos ocupa, en ningún momento, ni siquiera en las explicaciones míticas, las amazonas conciben sólas. Por ejemplo, según los datos etnológicos de Estrabón ${ }^{22}$, éstas se aparean con los garamantes, o con otros grupos, dependiendo de la zona.

En cuanto a los niños de los "lunares", paridos únicamente por los hombres, Luciano nos otorga más claves de interpretación: son nacidosmuertos, puesto que la vida la obtienen poniéndolos de forma que puedan inhalar el viento, lo que coincide con el pneuma, que es quien da el hálito vital y el alma. Aspecto que se corrobora al explicar Luciano que "cuando un individuo envejece, no llega a morir, sino que se disuelve como el humo y se transforma en aire.

El tema de la procreación humana y especialmente el misterio de la vida, durante siglos, ha tenido un sesgo curioso por la carga ideológica que ha suscitado buscando un sistema coherente con las representaciones simbólicas. Según diversos autores, el ciclo que combina la caza, vinculada a los hombres, con la agricultura, llevada a cabo por las mujeres, e incluso el pastoreo con la agricultura, configura un sistema de creen-

es aire, como afirman algunos, incapaces de concebir que tuviera una naturaleza incorpórean. Isidoro DE SEvilla, Etimologías (Madrid: Biblioteca de Autores Cristianos, 1983), libro XI, 7-8.

20 En la epopeya oseta, la madre del héroe narto Batraz es un ser sobrenatural (con características melusinianas) que queda en cinta de un granjero. En el momento en que es descubierta su naturaleza debe partir, pero antes "soplará" en la espalda del padre de Batraz el embrión que se desarrollará allí hasta el parto, momento en el que se tendrá que abrir el acceso de su espalda. Cf. Georges DumÉzil, Romans de Scythie et d'alentour (Paris: Payot, 1978).

21 Georges Devereux, Femme et mythe (Paris: Flammarion, 1982), p. 321.

22 Estrabón, Geografía de la Península Ibérica, XI, 5, 5. Edición de Antonio García BELlido, España y los españoles hace dos mil años (Madrid: Espasa-Calpe, 1980). 
cias que valorizan a la diosa madre y las facultades de la mujer en el proceso de la generación, especialmente desde el neolítico hasta la edad de bronce, durante más o menos tiempo según la zona concreta del Mediterráneo. Sin embargo, en la Grecia clásica pronto se minimiza el papel de la mujer, convirtiéndola en simple receptora de la simiente masculina.

Los presocráticos, más atentos a la naturaleza que a la urazón jerárquica", creían que tanto el padre como la madre aportaban un equivalente genético. Parménides de Elea (circa 519 a. C.) manifiesta que la mujer también produce una semilla. Según Empédocles (circa 483/430 a. C.), cada padre produce una semilla que contiene en estado disperso todas las partes del feto, y que se unen al estar juntas. Pero el niño sólo empezará a respirar en el momento del nacimiento. ¿Será entonces cuando tendrá alma? La escuela de Hipócrates tenía el mérito de dar una explicación coherente al doble aporte parental y de la herencia genética. Sin embargo, Aristóteles (384-322 a.C.), a diferencia de Hipócrates, estima que sólo el principio prolífico se contiene en la simiente del hombre, bajo la forma de un fluido etéreo y sutil. ¿Intenta Aristóteles suplir el viento fecundante con otro mito racionalista?

Mientras que la teoría de la doble simiente mina todo pensamiento misógino en materia de procreación, Aristóteles aporta en sus teorías una gran misoginia: en su sistema, el hombre es causa eficiente de la vida y del movimiento. Es el hombre el que insufla el alma a la materia muerta abastecida por la madre. Esquilo en Las Eumenides y Eurípides en La Orestiada se hacen partícipes, en el campo del imaginario, de que la madre es un depositario extranjero y es del padre de quien se recibe el gen, manifestando, por lo tanto, un orden jerárquico. Para Aristóteles ${ }^{23}$, la mujer, desprovista de semen, es sólo un macho imperfecto (nos recuerda esto teorías más modernas). El hombre, por su naturaleza, es superior, más "divino". Isidoro de Sevilla señala en su Etimología ${ }^{24}$ que la palabra Mater equivale a materia; el padre, en cambio, es la causa.

En la Edad Media, y en el área mediterránea, los médicos andalusíes Avicena y Averroes recogen la herencia de Aristóteles. El Renacimiento no aporta nada nuevo: Paracelso, Bacon y Van Helmt se inspiran en Aristóteles, mientras que Paré, Liebault, Leonardo da Vinci y Falopio proclaman su relación con el pensamiento de Hipócrates ${ }^{25}$.

De Hipócrates a Descartes los progresos no son desdeñables, pero la explotación de un pensamiento poco fecundo desde un punto de vista

23 ARISTÓTELES, op. cit.

24 Isidoro DE SEVILlA, op. cit., vol. I, libro IX, 5, 6, p. 785.

25 Pierre DARMON, Le mythe de la procréation à l'âge baroque (Paris: Editions du Seuil, 1981), p. 41. 
propiamente científico se traduce por la expansión de un sentimiento misógino: “El licor seminal es para la generación lo que el escultor al mármol", todavía dice Dubuisson a principios del siglo XIX en un comentario del sistema de Aristóteles. En otros términos y para dar una expresión del siglo XVIII, la mujer, en su función puramente pasiva, sólo asegura "la cama y la cobertura". En el mismo sentido, Darmon recoge en su estudio: "La mujer — se burlaba Voltaire- sólo es una gallina blanca en Europa y una gallina negra en África" ${ }^{26}$.

Uno de los tópicos de los análisis culturales es la vinculación de la mujer como individuo más próximo a la naturaleza, mientras que el hombre lo está a la cultura. La mujer aparece, según las culturas y la época, con un estatus ambiguo, a veces peligroso, que le confiere un carácter mediador entre la naturaleza y la cultura, asignándole significados polarizados y contradictorios ${ }^{27}$. A este resultado ya había llegado, a mediados del siglo pasado, el jurista y filólogo suizo Johann Bachofen ${ }^{28}$, que recogió de las fuentes clásicas un compendio de datos que, según él, ponían de manifiesto una realidad social diferente que otorgaba un papel predominante a la mujer. Para lograr la comprensión de un sistema de Derecho, es necesario conocer los principios o las ideas básicas que definen todos y cada uno de los caracteres del sistema; cuando se cambia un principio, se altera el conjunto de los elementos del sistema. Por ejemplo, el Derecho romano se asienta en una serie de principios entre los que ocupa un papel preponderante la idea de la paternidad y la autoridad del paterfamilias. Partiendo de estos presupuestos, Bachofen orientará sus investigaciones hacia el descubrimiento de un sistema jurídico muy arcaico basado en la autoridad de las madres ${ }^{29}$. Y para el análisis de este sistema ya desaparecido considera como fuente primordial el mito. Para Bachofen, el mito, multiforme y cambiante en su aspecto, sigue, no obstante, leyes determinadas, y no es menos rico en resultados firmes y sólidos que cualquier otra fuente de conocimiento histórico.

26 Op. cit., pp. 44-53.

27 Sherry B. ORTNER, "EEs la mujer con respecto al hombre lo que la naturaleza con respecto a la cultura?n, O. HARRIS y K. YOUNG (eds.), Antropología y feminismo (Barcelona: Anagrama, 1979).

28 Johann Jakob BACHOFEN, Il matriarcato. Ricerca sulla ginecocracia del mondo antico nei suoi aspetti religiosi e giuridici (Turín: Giulio Einaudi, 1988), 2 vols.

29 Este compendio se centraba básicamente en zonas del Mediterráneo preindoeuropeo, como Lesbos, Licia, Creta, Lemnos, Egipto, Mantinea, Atenas y Libia entre los siglos VIII y III a. C. Bachofen en Das Mutterrecht (El matriarcado, op. cit.) plantea de forma evolucionista las tesis sociológicas que luego adaptarían Morgan y Engels. La sociedad ha pasado por tres niveles: 1) heterismo o sociedad promiscua, 2) ginecocracia o sociedad matriarcal y 3) sociedad patriarcal o civilizada. 
A pesar de la confusión entre filiación matrilineal y matriarcado o gobierno de las mujeres, cosa muy diferente y nunca confirmada como etapa evolutiva, debemos a Bachofen el primer estudio demostrativo de la filiación uterina y de los elementos matriarcales-agrícolas, cuyas características se observan en diferentes sociedades a través del tiempo. Al referirnos a rasgos matriarcales debemos hablar más de tendencias que de predominancia absoluta de la mujer, aunque existen conjunciones de elementos religiosos y sociales que favorecen su papel.

\section{LA COVADA: IMITACIÓN DE LA NATURALEZA}

La vinculación tópica del hombre a la cultura y de la mujer a la naturaleza hace de la covada un elemento oscuro, debido a sus implicaciones con la imitación de la naturaleza. Rito de paso, como brevemente la había catalogado Van Genep, la covada es la parodia del parto que efectúa el marido, mientras que la mujer disimula el acto de dar a luz. Ésta es la definición más extendida sobre el rito que, como todos sabemos, es de carácter simbólico, puesto que el hombre finge (o no) los dolores de parto y se acuesta junto al niño recién nacido, siguiendo una dieta determinada y recibiendo las felicitaciones por su paternidad. Esta característica es considerada por algunos antropólogos como propia de los pueblos matrilineales que, no obstante, reconocen la paternidad del hombre.

Según R. Briffault, el rito de la covada sirve para destacar la relación indisoluble entre el marido y el grupo de la mujer que interviene en el nacimiento del niño. Mientras que Malinowski afirma que la costumbre de la covada conlleva que la paternidad se establezca simétricamente por reglas según las cuales el padre imite los tabúes y las prácticas impuestas a la madre. La función de la covada representa el establecimiento de la paternidad social por asimilación simbólica del padre a la madre ${ }^{30}$. En algunas culturas es un aspecto profiláctico, puesto que el hombre sirve de señuelo para los malos espíritus. Sin embargo, otros antropólogos ven en la covada un rasgo primitivo del patriarcado, puesto que es al hombre a quien se reconoce socialmente y al que se considera susceptible de transmitir el nombre, o sea, el linaje.

La covada no es universal, pero teniendo en cuenta el conocimiento etnográfico, que se ha ido ampliando desde el siglo XIX, parece que se ha dado en puntos muy alejados del planeta. Desde mediados del siglo pasado cobró impulso con mayor o menor fortuna en la etnografía en Europa,

\footnotetext{
30 R. Briffault, "Birth Customs", Encyclopedia of the Social Sciences, vol. IV, p. 631.
} 
hasta los años cuarenta del siglo $\mathrm{xx}$ - a excepción de algunos trabajos centrados en Brasil que consideran el tema de forma muy diferente ${ }^{31}$.

En las últimas décadas, el tema ha sido retomado por los psicólogos -que han entrado directamente en el terreno del mito-, evidentemente ámparandose en los datos etnográficos, aunque luego su interpretación haya tomado un cariz más internalista. Bruno Bettelheim ${ }^{32}$ nos habla del macho envidioso, ya que ve en el ritual de la covada un rito de hombres, y está en desacuerdo con la aproximación de Briffault, quien en su estudio considera este aspecto como un elemento simpatético de imitación. El psicoanalista encuentra que el hombre tiene bien poca simpatía por la mujer, haciéndola saltar del lecho cuando es ella la que tiene los dolores del postparto. Bettelheim, sin negar lo dicho por los antropólogos funcionalistas, desde su ángulo psicológico, ve en este ritual la necesidad del macho de decir que él también puede dar a luz.

En los alumbramientos de Atenea y de Dionysos por parte de su padre, Zeus, el etnopsicólogo George Devereux ${ }^{33}$ ve también ejemplarizaciones del rito de la covada. En la expresión del mito, Atenea surgirá de su cabeza y Dionysos de su muslo. De hecho, no se trata de una partenogénesis, pues para lograrlo, Zeus primero deberá tragarse a Metis, que está embarazada, consiguiendo de esta forma que el embrión de Atenea pase a su cuerpo. Otro tanto hará con Semelé, madre de Dionysos, al cual Zeus arrancará del vientre de su madre y lo introducirá en su propio muslo (cuisse de Jupiter), recosiéndolo de nuevo hasta el momento apropiado. Los nacimientos femorales o cefáleos de Zeus no excluyen el papel de la madre en la concepción ${ }^{34}$, sino que se manifiesta una volun-

31 Según P. MENGET, la sustitución simbólica de la madre por el padre, constitutiva de la costumbre en Europa, es rara o ausente entre los americanos. Para este autor, Claude Lévi-Strauss, en La pensée sauvage (Paris: Plon, 1969), tuvo el mérito de ser el primero en situar el problema de manera general: "Sería falso decir que el hombre toma el lugar de la parida. Marido y mujer están obligados a tomar las mismas precauciones, para confundirse con su hijo que, en las primeras semanas o meses después del nacimiento, está expuesto a grandes peligros. Así, como ocurre a menudo en América del Sur, el marido toma aún más precauciones que su mujer porque, en razón de las teorías indígenas sobre la concepción y la gestación, es particularmente su persona la que se confunde con la del niño"; Patrick MENGET, "Temps de naître, temps d'être: La couvade", Michel IZARD y Pierre SMITH (eds.), La fonction symbolique. Essays d'anthropologie (Paris: Gallimard, 1979), p. 246.

32 Bruno Bettelheim, Heridas simbólicas. Los ritos de pubertad y el macho envidioso (Barcelona: Barral, 1974).

33 Georges Devereux, op. cit., p. 168.

34 Véase, por ejemplo, el caso de Batraz, citado más arriba (Georges DumÉzIL, op. cit.). 
tad de dar a luz. Venir de cuixa es una expresión patriarcal de origen latino, que se utilizaba en el reino catalano-aragonés para designar a aquellas personas más próximas a la familia ${ }^{35}$.

La palabra Genos implica raza, linaje, además de prestar su raíz al término geniculum (rodillas). Según Isidoro de Sevilla "cada geniculum es el propio, sancionado siempre por el matrimonio". El filólogo Joan Corominas ${ }^{36}$ dice que el geniculum aparece ya en los textos del siglo $\mathrm{v}$, y puede constatarse en él una tendencia a relacionar las partes sobre los hijos femorales, con el nacimiento, siempre dentro del linaje paterno o, por lo menos, incidiendo en que el padre tiene un papel fundamental. En Galicia, cuando los padres no estaban casados, y el hombre no reconocía al hijo, se decía que tenían "dos xeollos queimados" ${ }^{37}$; tenían las rodillas quemadas porque no eran capaces de transmitir su linaje a sus descendientes.

\section{LA COVADA, RITUAL JURÍDICO DE RECONOCIMIENTO PATERNO}

Escribir sobre la covada a finales de la última década del siglo $\mathrm{xx}$ es un reto para la antropología, teniendo en cuenta que es un aspecto que ha rayado en la fabulación y que sobre todo ha despertado grandes pasiones entre algunos eruditos, que se han visto en la obligación de defender su "orgullo étnico", negando que tal costumbre se produjese en su región. Intentaré dar una explicación sociocultural a la luz de los datos etnográficos recopilados por diversos autores clásicos y modernos, de la Encuesta del Ateneo de Madrid realizada entre 1901-1902, así como a través del trabajo de campo que efectué en las islas Baleares entre 1985 y 1987.

En relación a la covada existen diversas aportaciones en los textos clásicos: Apolonio de Rodas habla de los Tibarenios, población escita lo-

35 El derecho de pernada o "dret de cuixa" figura entre los abusos tradicionalmente atribuidos a los señores feudales, aunque nunca fue autorizado por ley escrita. El abuso de forma ocasional podía ser que el señor pasara la primera noche con la esposa del siervo y de forma simbólica cuando la mujer estaba acostada en la cama pasar por encima de ella. Ambas formas son mencionadas por los payeses de remensa en el proyecto de concordia de 1462 y explícitamente prohibidas en la sentencia arbitral de Guadalupe (1486).

36 Joan Corominas, Diccionario crítico etimológico castellano e bispano (Madrid: Gredos, 1980), vol. II.

37 Manuel MANDIANES, Loureses. Antropoloxia dunba parroquia galega (Vigo: Galaxia, 1984), p. 109. 
calizada en el Ponto; Diodoro habla de una población corsa; Estrabón de los cántabros en la Península Ibérica; Plutarco de los Chipriotas. Veamos lo que escribe Apolonio en su Argonáutica:

Cuando las mujeres dan a luz a sus hijos, son los maridos quienes gimen echados en el lecho con la cabeza vendada. La cabeza vendada irecuerda, quizás, el parto cefálico de Zeus, o también, quizás, porque el esperma, según los griegos, viene de la cabeza?, y las mujeres preparan la comida para ellos y les preparan el baño ritual para el parto ${ }^{38}$.

Bachofen ${ }^{39}$ en su estudio comenta los versos precedentes y añade la versión de Ninfodoro en la Consuetudini: “Tibarenios, pueblo de la Escitia. En el país de los Tibarenios las mujeres cuando parían cuidaban a los hombres". La aplicación de esta norma, que se da también en los otros pueblos y que venía seguida de una fiesta, o por lo menos de visitas sociales, es para Bachofen la manifestación de la bilateralidad, ya que en un principio el hijo sólo lo es de la madre. El padre viene a figurar como una segunda madre. De hecho, en el mito de Dionysos, a éste se le denomina "bimater" porque tiene el doble nacimiento, primero de la madre y después del padre. Bachofen, que también trabajó sobre el ethos o comportamiento desde un punto de vista social y psicológico, comenta en relación a la fiesta celebrada por los Tibarenios que la madre tiene una posición importante, mientras que el padre debe pasar a través de la ficción de la verdad natural de la maternidad a fin de obtener el reconocimiento de la propia masculinidad, la cual no posee por su naturaleza. Para Bachofen, en este caso, el ritual de la covada está claro: es el paso manifiesto del reconocimiento paterno. Una especie de "legitimidad.

En cuanto al hecho de que las mujeres paren y saltan del lecho para que lo ocupen sus maridos, tendríamos que tomarlo de una forma menos literal: entre el nacimiento y el ritual, que es cuando se celebra la fiesta puede pasar desde muy poco tiempo a quince días, como explicaré más adelante, en relación a mi trabajo de campo en Formentera, dependiendo de la fortaleza de las mujeres y de la costumbre de la zona.

A Julio Caro Baroja debemos el primer estudio sistemático sobre la cultura matriarcal de los pueblos septentrionales de la península Ibérica. Caro Baroja se manifiesta partidario de usar el término derecho materno en vez del solemne matriarcado de Bachofen. Entre los datos aportados por los autores clásicos el derecho materno cántabro, referido por el geó-

38 APOLONIO DE RODAS. El viaje de los Argonautas (Madrid: Editora Nacional, 1975), versos 1000-1050, pp. 123-124.

39 Johann J. BACHOFEN, op. cit. 
grafo griego Estrabón ${ }^{40}$ (s. I a. C.), únicamente es comparable, en cuanto a precisión al de Herodoto en relación con los licios. El antropólogo manifiesta que ni Herodoto ni otros autores que hablan de ginecocracia llegan a indicar características de orden económico tan fundamentales como las proporcionadas por Estrabón sobre los pueblos cántabro-astúricos, donde eran las mujeres las que dotaban a sus hermanos en el matrimonio. Sobre el ritual vinculado al nacimiento nos habla de la covada, o sea, del acto mediante el cual el hombre sustituye a la mujer en el lecho como si fuera él quien ha dado a luz; rasgo característico que Estrabón considera "poco civilizado" ${ }^{41}$.

Caro Baroja, en Los pueblos del Norte, obra publicada en 1946, introduce el estudio más definitorio, al menos dentro de la antropología ibérica. Con su prudencia característica y haciendo acopio de las fuentes existentes comenta:

No creo que esta moda o costumbre tenga la importancia general que se le ha querido dar a partir del antropólogo Tylor, pero parece evidente que no puede provenir más que de la idea de participación del hombre en el acto de procreación, y que según qué punto de vista se practique, puede tener una significación $\mathrm{u}$ otra, puede ser un acto jurídico, o puede ser un acto mágico ${ }^{42}$.

En esta obra, Caro Baroja realiza un exhaustivo estudio de los textos clásicos sobre la covada y rastrea el mito literario que convierte la "original covada cántabra" de los pueblos ibéricos septentrionales en "covada vasca". Se trata de un ritual que en el siglo XIX ya no tenía lugar; sin embargo, según el autor, la covada ha podido existir en el País Vasco hasta el siglo xviII. El mismo autor añade: "Lo curioso es que ha producido la atribución a los vascos reacciones airadas de algunos eruditos que, además, nos han condenado incluso a los que, desde lejos, hemos hablado del asunto" ${ }^{43}$.

\section{LA COVADA EN LA ENCUESTA DEL ATENEO DE MADRID (1901-1902)}

A través de los datos de la encuesta hecha en 1901 por el Ateneo de Madrid $^{44}$, sobre el nacimiento, el matrimonio y la muerte, don Telesforo

40 Estrabón, Geografia... Edición de Antonio García Bellido, op. cit.

41 Op. cit., III, 4, 17.

42 Julio Caro Baroja, Los pueblos del Norte (San Sebastián: Txertoa, 1977), p. 226.

43 Ibid

${ }_{44}$ En 1901 apareció la encuesta Información promovida por la sección de Ciencias Morales y Politicas del Ateneo de Madrid, en el campo de las costumbres populares 
de Aranzadi ${ }^{45}$ recogió de modo directo la noticia de que en los valles de Pas (Cantabria) y Poza (Burgos), ula covada había existido hasta la segunda mitad del siglo xIx, en que un parroco enérgico la suprimión. Caro Baroja recuerda, asimismo, que en el trabajo de Enrique Casas ${ }^{46}$ hay poca cosa referente a España, mientras que considera un texto categórico sobre la covada en León, entre los maragatos, de don León M. Granizo, que dice:

En cierta parte de León y muy cerca de Astorga, se da una extraña costumbre que no quiero dejar de referir. Esta es la conocida "cobada" o "acobada" que, entre algunos maragatos, tiene un poder misterioso como influjo ancestral. En ciertas ocasiones, que un ilustrado amigo nos decía con pena: "iQué quiere Usted! Yo, cuando llega esta ocasión, no lo puedo remediar, e irresistiblemente soy débil y la practicon. Pues bien, la covada consiste en acostarse el padre con el hijo recién nacido, y en dejarse cuidar con mimo, como si él fuera ciertamente quién salió del cuidado ${ }^{47}$.

Sánchez Pérez estudió las 81 papeletas del cuestionario del Ateneo de Madrid que hacían referencia a la covada. Para este autor, la covada, primitivamente, no debía ser otra cosa que la justificación de la paternidad, a lo que Nieves de Hoyos Sancho comenta:

Dos explicaciones tiene para nosotros [el análisis de las 81 papeletas citadas]: la covada en parte es tal vez fundamentalmente el resto de una tradición del matriarcado al patriarcado, psicológicamente análoga a la de otras interpretaciones folklóricas, del vulgarísimo concepto de sudar el padre al hijo para transmitirle con sus humores sus caracteres, sustituyendo o al menos compartiendo con la madre la transmisión directa de las cualidades por la sangre ${ }^{48}$.

y en los tres bechos más característicos de la vida: el nacimiento, el matrimonio y la muerte, de la cual se hicieron dos ediciones. El cuestionario fue realizado por R. Salillas, J. Puyol, C. Bernaldo de Quirós, E. García Herreros, G. Pedregal y R. Camarón. Las copias del cuestionario se enviaron a pueblos de toda España, recibiéndose en el Ateneo 189 constestaciones correspondientes a un número mayor de localidades, que pueden ser estimadas en alrededor de 350. La transcripción de dicha encuesta se encuentra publicada en el Museo del Pueblo Español de Madrid. Cf. Antonio Limón y Eulalia CASTEllote (eds.), El ciclo vital en España. Encuesta del Ateneo de Madrid 19011902, (Madrid: Museo del Pueblo Español, 1990), 2 vols.

45 Telesforo DE ARANZADI, "La covada en España", Antbropos, 1910. Citado en Julio Caro Baroja (op. cit.).

46 Enrique CASAS, La covada y el origen del totemismo (Editorial Católica Toledana, 1924).

47 Citado en Julio Caro Baroja, op. cit., p. 218.

48 Nieves DE HOYOS SANCHO, "Ginecocracia o mando de las mujeres en España", Las Ciencias, XI, n. ${ }^{\circ}$ (1946), p. 303. 
Caro Baroja, en resumen, encuentra que desde el Pirineo hasta la frontera de Galicia hay más que indicios de haberse practicado la covada de la manera como la describió Estrabón o de otra. Pero resulta que rastreando la encuesta ésta aparece en lugares muy alejados, como las Baleares y en las Canarias, precisamente los lugares en los que se mantendrá durante más tiempo. Que esto fuera recogido por el historiador Antonio García Bellido ${ }^{49}$, así como en otras publicaciones, entre ellas las del mismísimo Caro Baroja, desató una polémica que iba desde las columnas de los diarios locales a los prólogos de las obras científicas, como el que hizo Julio Caro Baroja a un libro de Enrique Casas Gaspar de 1947, donde el entonces joven antropólogo presenta un prólogo valiente y reflexivo, teniendo en cuenta la época en la que se escribe, cuando ni las instituciones ni los censores apostaban demasiado por el positivismo.

\begin{abstract}
Hace unos meses cierto amigo y condiscípulo mío de los años universitarios, que se halla ejerciendo su oficio en la isla de Ibiza, me mandó un recorte de un periódico local ${ }^{50}$ en que, de manera bastante áspera, se exigía a los eruditos en general que rectificaran la noticia difundida en algunas publicaciones (entre ellas una mía) sobre la existencia más o menos remota de la práctica de la covada en aquella isla. Según el autor del artículo, lo que se decía y repetía en este sentido era producto de mala voluntad de los pobladores de alguna isla vecina ${ }^{51}$.
\end{abstract}

El autor al que se refería Caro Baroja no era otro que el erudito ibicenco Mossen Isidoro Macabich, autor de la célebre Historia de Ibiza, y que más tarde publicaría el mencionado artículo y otros muchos materiales en sus Obras Completas. Macabich continúa con los datos aportados por Casas Gaspar, Caro Baroja, Sánchez Pérez y la inevitable Encuesta del Ateneo de Madrid, sobre la que don Isidoro da por supuesto "mientras no se demuestre lo contrario, que sobre las Baleares fue contestada desde Palma de Mallorca" ${ }^{52}$. También se siente vejado porque García Bellido introduzca a Ibiza entre sus referencias a la covada: "su cita podría venir a dar por buenas, por su alta procedencia, unas viejas invectivas burlescas que, antes que a nosotros, encendieran la sangre a muchos ibicencos" ${ }^{53}$.

49 Antonio García Bellido, op. cit.

50 Diario de Ibiza, 31 de octubre de 1946. Poco después de la aparición de la publicación de García Bellido, Mossen Macabich sigue las fuentes y se entera de que lo que afirma García Bellido lo toma de la obra de Caro Baroja, Los pueblos del Norte.

51 Julio CARO BAROJa, "Prólogo", Enrique CASAS GASPAR, Costumbres españolas de nacimiento, noviazgo y muerte (Madrid: Escelicer, 1947), p. 10.

52 Isidoro MACABICH, Obras Completas, Vol. II, pp. 350-355.

53 Ibid. 
Entre las preguntas que se formularon en la encuesta realizada por el Ateneo de Madrid, en diversos lugares de la geografía hispana, figuraba un apartado sobre el papel del padre en el alumbramiento: "Existe la covada o costumbre de permanecer el padre durante cierto tiempo en el lecho que ocupan la madre y el hijo, u otras prácticas análogas?" En las líneas que siguen nos ocuparemos especialmente de las respuestas al cuestionario procedentes de las islas Baleares. Veamos, pues, lo que contestaron los informantes "baleáricos" de principios de siglo. El informante de Mallorca (Palma) dice:

La covada se puede afirmar que no existe en esta región. Tenemos, sin embargo, la seguridad de haber existido en épocas antiguas. Hoy se observa en la clase proletaria y población rural que el marido no abandona el lecho de su esposa. En donde está más marcada la covada es en la vecina Ibiza. Tan pronto como se presenta el parto, el marido se mete en la cama con su mujer, tomando tazas de caldo como ella y colocando al niño entre ambos.

El informante del pueblo de Santa María (Mallorca) abunda en este sentido: "No existe en Mallorca la covada. Se dice empero que ha existido en Ibiza, reminiscencias sin duda de vascos y celtas".

$\mathrm{Y}$ en la isla de Menorca contestaron: "No estamos en la época de la covada. Al padre que en vez de desplegar su actividad, se tumba a la bartola, se le aplica el mote de 'parterot', masculino de partera (recién parida, según nuestro dialecto)".

Mossen Macabich —uno de los eruditos más preocupados por el honor de su isla y gran polemizador a través de los diarios locales en los años cuarenta- afirma que la covada en Ibiza jamás tuvo lugar. Sin embargo, durante el trabajo de campo que llevé a cabo en las islas Baleares en la década de los ochenta, pude observar cómo en Mallorca todavía hoy cuentan historias de los años veinte y treinta sobre algunos aspectos relacionados con la covada en Ibiza. Un hombre de setenta y cinco años, que estuvo embarcado durante un largo período, dijo que un compañero ibicenco con el que había convivido largas jornadas le había contado que "en su tierra - y él mismo-, cuando tenían un hijo, iban las mujeres a felicitar a la esposa. El marido se colocaba dentro del lecho y las señoras le saludaban diciendo: "Que Déu vos guard es consolador" [Que Dios os conserve el consolador], al tiempo que le tocaban por encima de la sábana el órgano sexual. En 1985 en la isla de Formentera ${ }^{54}$

$<54$ Formentera, que administrativamente formaba parte de Ibiza, estuvo despoblada durante tres siglos desde el final del XIV. Cuando más atacaron los turcos, fue una estación continua de los piratas argelinos. La mayor seguridad y la presión demográfica ibicenca motivaron que Formentera se poblara de nuevo con ibicencos desde 
encontré dos informantes del municipio de Sant Francesc, mayores de setenta años, que aseguraron ser esto cierto pero que no se empleaba el eufemismo del "consolador", sino que la fórmula era la siguiente: "Que Déu vos guard s'emprenyador" (Que Dios os conserve el preñador), o sea el órgano que sirve para preñar a la madre, ritual que sus abuelos y padres habían observado.

Mossen Macabich se quejaba precisamente de que desde Mallorca se había difundido el mito de la covada por el hecho de que las madres en Ibiza no recibieran a nadie durante quince días, al cabo de los cuales se hacía una fiesta denominada de "Ses comares" (de las comadres). Macabich cita como avalador del tema el artículo "La Fiesta de las Comadres" del sacerdote mallorquín D. José Rullán ${ }^{55}$, autor de varios escritos sobre costumbrismo ibicenco.

En Mallorca, como en otros lugares, la mujer que pasa a ser madre, en los momentos que necesita mayor sosiego se vé asediada por visitas inoportunas que contribuyen a quebrantar su delicada salud, a aumentar las dolencias o motivar enfermedades de resultados fatales. En Ibiza sucede todo lo contrario: y esto bastará para convencer a los incrédulos, que no pasa de maliciosa broma o de grosera calumnia, lo que afirman algunos viajeros al decirnos que, después del bautizo, el padre se acuesta, recibe las visitas y es regalado por su consorte durante muchos días.

Macabich, obsesionado por el tema, vuelve a reproducir, esta vez entero, el artículo de Rullán ${ }^{56}$, bajo el epígrafe de La fiesta de las Comadres, del cual transcribo un fragmento que me parece significativo en base al tipo de parentela de "comadres" que se invita:

Restablecida la enferma - la mujer recién parida-, con aviso anticipado hace saber a sus hermanas, cuñadas, tías, parientas y amigas íntimas, casadas, sin olvidar a los padrinos de la criatura, el día que recibirá visitas y celebrará la Fiesta de las Comadres. Acuden las invitadas con regalos y se les obsequia luego con una comida.

Don Isidoro se sale de sus casillas diciendo: "Aquí no han covado nunca los hombres, que han sido siempre muy hombres. Sólo han covado las lluecas". Crea aquí Macabich un neologismo, a partir de la palabra catalana "lloca" y la castellana "clueca". En Mallorca y Valencia, según el Dic-

1697. Podemos decir, así, que las costumbres de Formentera son las mismas que las de Ibiza.

55 Isidoro MACABICH, op. cit., p. 353.

36 Historia de Ibiza (Palma de Mallorca: Daedalus, 1966-1967), vol. IV, pp. 127-130. 
cionario Moll, una de las acepciones de la palabra "lloca" es la de un hombre inactivo y cobarde. Macabich se sintió varias veces llamado a rechazar todo aquello que, según su criterio, pecara contra el pudor o fuera bárbaro: en el volumen IV de su Historia de Ibiza ${ }^{57}$, dedicado al costumbrismo, encontramos un nuevo artículo, esta vez para contestar otro del mismo Vicente Blasco Ibáñez, en el que, hablando sobre las peculiaridades de Ibiza, hace una descripción de los cortejos ibicencos, donde varios jóvenes acuden a la casa de la muchacha que quieren cortejar y ésta les recibe por tiempos, de uno en uno, mientras que los otros esperan. Esto le sabe muy mal a don Isidoro, quien, sin embargo, encuentra muy acertado que el escritor valenciano escriba que "los ibicencos son en su patriotismo de un valor ciego que no omite obstáculos" ${ }^{58}$.

Con todo, Mossen Macabich aporta, en los dos artículos, referencias muy valiosas sobre la covada. Por un lado, niega que exista la covada, ya que algunos autores que hablan de Ibiza —como el mismo Archiduque Luis Salvador (1868) - no lo comentan; pero, por otro lado, aprovecha la ocasión para buscar datos sobre Mallorca que confirmen el ritual atribuido a Ibiza: "En Mallorca, los visitantes del recién nacido tocaban el miembro viril al encamado padre y le felicitaban ritualmente diciendo: Déu mantenga s'emprenyadó. Y devuelve la pelota a los mallorquines refiriendo un estudio sobre "Los orígenes de la raza ibérica", publicado en el semanario El Español por el Marqués de Dosfuentes, con fecha 18 de agosto de 1945:

Esta costumbre llamada covada, que ha perdurado hasta hoy en el reino de Mallorca, me fue explicada [...] con la fórmula sacramental que alli se emplea. El marido con ropa de fiesta tendido en el lecho conyugal, recibe los homenajes de sus parientes, deudos y familiares, que desfilan ante él, le dan la mano y le dicen estas solemnes y expresivas palabras: Norabona al emprenyador, que no necesita traducción.

Tal vez atendía, el de las Nou Casas [continúa don Isidoro] a la tradición familiar, porque después de citar la costumbre bearnesa de meterse el padre en el lecho con el hijo, mientras que la recién parida atiende los menesteres del hogar, y en tal situación recibe aquel felicitaciones de los convecinos; añade la enciclopedia Espasa en su artículo La covada, que esa costumbre se ha referido a los mallorquines ${ }^{59}$.

Esta disputa, que tuvo lugar a finales de los años cuarenta de este siglo, lejos de negar el rito, no hace más que reafirmarlo. Por otro lado,

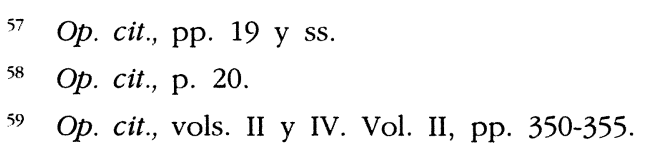


la descripción hecha por mis informantes de Formentera en relación a la "festa de ses Comares" concuerda con otras descripciones de la península Ibérica menos recientes pero más cercanas que las fiestas de los Tibarenios y de los Cántabros, con una importante participación matrifocal, o sea, de las mujeres, y especialmente de las casadas. Los quince días de los que tenemos constancia que transcurrían en el siglo xx entre el nacimiento y la fiesta, podían ser bastantes menos en épocas pasadas. Es posible que la fiesta se realizase el mismo día, según los datos que los escritores grecolatinos daban a propósito de la fortaleza de las mujeres montañesas de la antigüedad.

Entre las respuestas dadas a la encuesta del Ateneo, la del Puerto de Tamarite (Huesca) es bastante explícita:

No se conoce aquí la covada, pero algo que debe parecérsele cuentan que ocurría en la montaña de esta provincia a principios del siglo XIX. Y porque el hecho es escabroso de contar y no muy pulcro, refirámoslo [dice el informante] en aquel latín que a trompadas y palmetazos nos enseñaban in illo tempore:

Geniale ad convivium, mulierum turba vocata prope lectum venit,

Quo jacent conjuges ambo.

Tacti! propudor! apte sindone parato

Apicen phali tamtum ut vir ostendere quat.

Alia post aliam cumque digito pulsant genitor,

Ave, clamantes, tu genitor, ave ${ }^{60}$.

Esta descripción, referida al XIX, quizás sea la que más se acerca a las explicaciones que me han dado en las Baleares cuando realicé la encuesta oral sobre la covada.

\section{ETIMOLOGÍA DE LA PALABRA COVADA}

La imitación de la naturaleza por parte del hombre en el ritual de la covada ha sido rechazada desde la época de Estrabón por su falta de civilización y su proximidad a la naturaleza, pero a la naturaleza femenina. Hemos podido ver cómo, en este sentido, se ha producido un rechazo por parte de los informantes y de aquellos eruditos que, como Estrabón, se consideraban "civilizados". En esta tesitura, observaremos algunos de los contenidos que popularmente se destilan de esta imagen en la

60 "Una turba de mujeres invitadas al banquete llegan junto al lecho en el cual están acostados ambos cónyuges, tapados a causa del pudor. El varón enseña tanto cuanto puede la punta del falo. Una tras otra, las mujeres lo tocan con el dedo diciendo en alta voz: ¡Viva el padre!n. 
palabra covada. Si bien actualmente el rito se encuentra erradicado, no así la expresión covar, que continúa completamente vigente.

El doctor José A. Sánchez Pérez, en una de sus obras ${ }^{61}$, señalará:

Los etnógrafos están interesados en proporcionarse datos acerca de la covada, por ser imprecisos los que conocen o resultar contradictorios en apariencia. La palabra covada no existe en el Diccionario de la Academia de la Lengua. No se explica la omisión de covada, siendo palabra que se conoce y usa en Galicia, León, Santander, Burgos, Salamanca, Baleares y Canarias, estando incluida en diccionarios enciclopédicos españoles, como el Espasa, y el francés Larousse.

Covar es un vocablo muy extendido en catalán, tanto en Cataluña, como en Valencia y Baleares. Una de las acepciones de covar del diccionario de Alcover es la de estar dentro del lecho fuera de las horas normales de dormir, sea por enfermedad, sea por pereza" ${ }^{62}$. También encontramos la acepción de covar un constipado: estar encamado para curarse del resfriado, y una acepción curiosa aplicada a no servir para nada: "No ser bo per covar ni per pondre" (No valer ni para poner huevos ni para incubarlos).

Existe en castellano y también en catalán el vocablo coba, que va más allá de lo que puede presumirse en su primera acepción. Si consultamos el Diccionario crítico etimológico castellano de Corominas ${ }^{63}$, quiere decir: "halago, conversación que se da a alguien para halagarle", y añade algo que nos interesa: "Vocablo incierto, quizás del verbo romance covar "empollar" y procedente del latín cubare: "acostarse", "estar echado"”. De las diferentes posibilidades, Corominas se inclina por lo que hacen las gallinas con los polluelos; coba en el sentido de covar "empollar la gallina", o en el sentido de hablar, de dorar la píldora a alguien que se deja engañar fácilmente, como en la conversación falsamente halagüeña. Parece, sin embargo, que covada aplicada a los hombres está formada del latín cubare, o sea "estar echado" y del incubar de las gallinas.

El ritual de la covada ¿no podemos considerar que tiene también algo de coba, en el sentido de halago desmesurado, precisamente aplicado a

${ }^{61}$ José A. SÁNCHEZ PÉREZ, "La covada", Investigación y Progreso, n. $7-8$ (julio-agosto, 1933).

${ }^{62}$ Són les deu i encara coves (Ampurdán, Mallorca, Menorca): Son las diez y aún covas. "Aviat hauràs d'anar a covar" (Pronto tendrás que ir a covar) le dicen a una mujer que está en los últimos tiempos del embarazo (Ampurdán). (Antoni M. Alcover y Francesc DE BORJA MOLL, Diccionari català-valencià-balear (Palma de Mallorca, 1954) (VI, 3, III).

${ }^{63}$ Joan COROMinas, op. cit., V, II, 103. 
un hombre que está acostado como si fuera él quien realmente ha empollado al recién nacido? En este sentido, y siguiendo el imaginario popular, un caso interesante en relación al vocabulario del ritual lo encontramos a principios de siglo en las islas Canarias, de la mano del Dr. Bethencourt, autor de las respuestas de estas islas para la Encuesta del Ateneo de Madrid. Dice Bethencourt:

Hasta hace unos 70 años, en las islas de Fuenteventura y Lanzarote los maridos, durante el puerperio de las mujeres, se constituían en estado de $\operatorname{sorrocloco}(a)$, que consistía en permanecer en la cama mientras lo estuviera la parida, haciéndose atender y servir como ella. Hoy ya no se acuestan los maridos en las referidas islas, pero continúan haciéndose agasajar al igual que sus mujeres paridas con cuanto les llevan a la cama, como chocolate, gallina, caldos, vino, etc. Comen y beben lo mismo, las mismas veces y durante el mismo número de días.

Bethencourt, en una nota adicional entre otras disertaciones de tipo filológico, se pregunta: "Buscando el origen de la palabra y atendiendo al valor fonético, me he preguntado algunas veces si debería escribirse sorrocloco, que podría equivaler a zorro-clueco. ¿Habrá alguna circunstancia en la vida del zorro aplicable al hombre en estado sorrocloco?".

Caro Baroja desecha una serie de elementos filológicos que Bethencourt propone en su informe, citando el nombre de otros estudiosos extranjeros que atribuyen a la palabra raíces vascas, pero ligadas a los aborígenes canarios (¿guanches?). Cree sin embargo que podría tener relación con lo propuesto por Casas Gaspar sobre una costumbre leonesa -que no aparece en la Encuesta del Ateneo de Madrid-: "El marido se mete en un cesto de paja y puesto en cuclillas cacarea" ${ }^{64}$.

Si lo de clueco podría tener sentido, la pregunta sobre la vida del zorro formulada por Bethencourt refleja en sí misma la parodia. Porque no es en la vida del zorro donde hay que buscar, sino al revés. En el imaginario podría tratarse de una comparación aplicada al hombre que come gallina aprovechando el parto de su mujer. Si atendemos el valor de engaño que en las consejas populares representa el zorro, animal que siempre se zafa de las faenas que hace realizar a los otros animales y de las que luego intenta sacar provecho, así como su afición a comer gallinas, la denominación popular de zorroclueco al padre en el ritual de la covada es realmente oportuna.

En mi encuesta oral he hallado elementos en este sentido, como el que aportaba en Deià (Mallorca) una señora de noventa años que había ejercido de comadrona en dicho pueblo durante más de cincuenta, quien

64 Julio Caro Baroja, op. cit., p. 226. 
comentaba: "los hombres comían lo mismo que la parturienta. Aprovechaban para comer gallinas e inflarse. Había alguno que me decía: Tengo unas ganas de que mi mujer dé a luz y asi comer gallina cocida...!!n.

No es de extrañar que en el imaginario popular exista una rondalla catalana recogida por Joan Amades ${ }^{65}$, según la cual antes eran los hombres los que parían los niños, pero las mujeres tenían que cuidarlos y amamantarlos después del nacimiento. Las mujeres pidieron a Nuestro Señor (al Bon Jesús) que los niños naciesen de ellas puesto que los alimentaban. Al Señor le pareció justa la petición y respondió favorablemente.

\section{LAS FACULTADES DEL VIENTO Y CÓMO SE HACEN LAS ENTRAÑAS}

La capacidad para engendrar y/o dar a luz no es suficiente para resolver el misterio de la vida, y menos todavía el misterio del alma. Al fin y al cabo, los animales también tienen el poder reproductor. Por esta razón, veamos algunos rituales que intentan asegurar una transmisión psicopompa entre los vivos y los muertos, rituales que se verán afectados por las viejas creencias cósmico-religiosas en un continuum cultural.

No creamos que en las Baleares se ha perdido el medio de que los espíritus familiares puedan proporcionar sus cualidades a los niños. Hoy en día muchas madres o abuelas continúan, como siguiendo una llamada primigenia, transfiriendo el pneuma por medio de las habas. Las abuelas mallorquinas, sean de Sóller, Deià, Andratx o Montuiri, saben que el primer alimento sólido que se dará a un niño, incluso mucho antes de destetarlo, serán tres habas chafadas. Hoy en día se dice que es para que el niño tenga un estómago fuerte, una "bona gana". En fin, características vitales. ¿O quizás para intentar preservarle de los malos espíritus?

Hemos visto anteriormente que, según el pensamiento presocrático, el viento transporta el alma de los muertos y es, al mismo tiempo, fecundador. Las habas son un alimento flatulento, o sea ventoso, que en la larga tradición contiene, asimismo, elementos mistéricos. Los pitagóricos se abstenían de comer habas porque decían que en ellas residían los espíritus de los muertos. En Roma se continuó la interrelación, pues las arrojaban en la festividad de los Difuntos. Si una planta brotaba de una de ellas y una mujer comía sus granos, resultaba grávida por un espíritu ${ }^{66}$.

${ }^{65}$ Joan AMADES, El folklore de Catalunya. Rondallística (Barcelona: Selecta, 1974), p. 53.

66 En otras culturas, como los ndembu estudiados por Victor Turner, dar a alguien su propio nombre implica una especie de reencarnación parcial de ciertos rasgos 
En la religión romana, los lemures o espíritus de los muertos, eran objeto de un ritual los días nueve, once y trece de mayo, que Ovidio nos refiere en los Fastos: durante los Lemuria, el padre de familia piadoso se levantaba a media noche $\mathrm{y}$, descalzo, arrojaba por la casa habas negras destinadas a los fantasmas o lemures, como rescate de los miembros vivos de su familia que, en caso contrario, podrían ser arrebatados. "Tiro estas habas y con ellas me redimo a mí y a los míos". Esto lo repetían nueve veces ${ }^{67}$.

Cien años más tarde, Plinio ${ }^{68}$ continúa diciendo que el haba se emplea en el culto de los muertos porque contiene el alma de los difuntos. De este modo, las habas, en tanto que símbolos de los muertos y de su prosperidad, pertenecen al grupo de los encantos protectores. En el sacrificio de primavera, representan el primer don llegado de debajo de la tierra, la primera ofrenda de los muertos a los vivos, el signo de su fecundidad, es decir, de su encarnación. Aspecto que liga la prohibición de Orfeo y la de Pitágoras -en el término de que comer habas era el equivalente de comer la cabeza de los antepasados- de compartir la comida de los muertos, uno de los medios de mantenerse en el ciclo de las reencarnaciones y de servirse de los poderes de la materia. El campo de habas egipcio, así llamado simbólicamente, era el lugar donde los difuntos esperaban la reencarnación. En época más actual, en Cartagena (Murcia), hace una treintena de años, el Sábado de Resurrección todavía arrojaban habas desde los balcones.

Un elemento que se acopla con el imaginario en la relación psicopompa de las habas se manifiesta en las rondallas ibicencas ${ }^{69}$ y catalanas (Joan Amades en la Rondallistica ${ }^{70}$, donde nos encontramos una titulada "La favereta", que no es otra cosa que la planta del haba que sirve de escalera para conectar el cielo con la tierra, por medio de la cual el protagonista trepa hasta San Pedro y vuelve a bajar).

En Sóller (Mallorca), el acto de dar al niño las tres favetes se llama enconar. También se denomina así en Ibiza al acto de dar al recién na-

corporales o de carácter. Sin embargo, cuando muere una persona estéril le dibujan una raya negra desde el ombligo hasta el sacro, significando que el muerto no debe volver a visitar el mundo de los vivos, que "ha muerto para siemprew. Victor W. TuRNER, La selva de los simbolos. Aspectos del ritual Ndembu. (Madrid: Siglo XXI, 1980).

67 Ovidio NASón, Fastos (Barcelona: Fundació Bernat Metge, 1997), vol. II, V, versos 419-440.

68 PLINIO EL VIEJO, Histoire Naturelle, libro VIII (Paris: Les Belles Lettres, 1952), y libro XVIII (Paris: Les Belles Lettres, 1972), XXX.

69 Isidoro MACABICH, Historia de Ibiza (Palma de Mallorca: Daedalus, 1966-1967), vol. IV, pp. 305-307.

70 Op. cit. 
cido una galleta o un trocito de pan bien masticado. Esta es una forma de hacerle las entrañas y de transmitirle las propiedades espirituales de los ancestros, que influirán en las características anímicas de la criatura.

Enconar, en diversos pueblos de Mallorca y Cataluña, significaba dar de mamar al niño alguien que no fuera su madre, cosa que se hacía frecuentemente mientras la madre esperaba la subida de la leche e incluso hasta que desaparecían los calostros. Por ello se intentaba que fuese una mujer de confianza ${ }^{71}$, y mejor que fuese una pariente ${ }^{72}$, ya que hacer las entrañas es una cosa sumamente delicada. Sabemos que en las vísceras es donde residen las cualidades de la persona ${ }^{73}$. Y en el lenguaje popular constantemente oímos: "Fulano no tiene entrañas", o "Quin fetge!" ("Qué hígado!n), o "Quin estòmac!" ( ‘Qué estómago!»), o "Mengana está enconada de fulana, ¿no ves que tienen las mismas ideas?", "Tener mala leche" (tener mal carácter). En catalán, así como en dialecto mallorquín, enconar tiene que ver con los hábitos y por lo tanto con la educación y con la transimisión de la manera de comportarse. Significa: inclinar, habituar, acostumbrar; ser semejante.

La antropóloga francesa Nicole Belmont, en un interesante artículo sobre cómo "educar" a los niños ${ }^{74}$, juega con el término francés "élever. Toma el ejemplo romano del padre que levanta del suelo al niño en el caso de que lo admita como suyo, pasando de la horizontalidad en la que se halla en estado natural a la verticalidad de la cultura. Belmont expone: "Confiriéndole con el gesto de la elevación estatus de ser humano, cosa que le compromete a "l'élever" en el sentido figurado de la palabra, es decir educarlon. Vemos de nuevo, a través de este ejemplo, un cierto antagonismo entre la naturaleza y la cultura, representando el padre la cultura y la potestad de convertir al hijo en ser humano. Sin duda, el papel del paterfamilias, como destacaba Bachofen, dentro del sistema romano representa un simbolismo adecuado, incluso en las expresiones.

71 En algunos pueblos hay costumbre de tener prevenida a una mujer (llamada enconadora, en Mallorca, y bétera en Cataluña) que sea de conducta intachable, de buena salud y que lleve un año o más de parida, a fin de que dé la primera tetada al recién nacido (Joan AmADES, El folklore de Catalunya. Costums... op. cit, p. 82).

72 En los países islámicos, de fuerte carácter endógamo, está sin embargo prohibido el casamiento entre los que han establecido lazos de leche.

73 La Enciclopedia Larousse española, a propósito de entrañas dice: “El vocablo suele usarse en plural y se refiere a los intestinos, órganos contenidos en la cavidad torácica e intestinal. Otra acepción es: voluntad, afecto del ánimo, índole y genio de una persona, lo más íntimo.

74 Nicole Belmont, "Levana, ou comment élever les enfants", Annales, 1 (1977). Cf. también "L'enfant exposé", Antbropologie et Sociétés, 4, n. 2 (1980). 
En la península Ibérica, la palabra educar, que viene del latín ducere, no se utiliza hasta el siglo xvII, mientras que la palabra criar - que quiere decir nutrir, alimentar, cuidar, instruir, educar, dirigir, producir, engendrar- es de viejo arraigo, y procede del latín creare (crear, engendrar, procrear). Como voz popular sólo se ha conservado en las tres lenguas romances hispánicas (catalán, castellano y gallego). Según el filólogo Joan Corominas, cuando la encontramos en sentido parecido en otras lenguas romances es tardíamente, y posiblemente préstamo de las ibéricas. Por lo tanto, en la península Ibérica, el simbolismo de la palabra que contiene el orden de la educación - es decir, de la transmisión - tiene connotaciones de participación de la naturaleza.

El término crianza no se usa solamente vinculado a la lactancia, sino que, unido a adjetivos "buena" o "mala", se refiere siempre a aspectos ligados a la educación y a la cortesía. En el campo de los cuidados desarrollados por el hombre para conseguir una cierta calidad en un producto natural, como es el vino, es interesante la utilización de la palabra "crianza" referida al conjunto de cuidados a que se someten los vinos después de fermentados (proceso de transformación) para acabar su formación y conferirles un punto perfecto.

Por lo tanto, enconar está dentro del proceso formativo de la crianza, que especialmente tendrá que ver con la formación de las entrañas, que es donde residen las cualidades anímicas de todo tipo. Este proceso formativo y de transformación depende de causas naturales que pueden ser fortuitas o inducidas.

Las cualidades y los defectos, o sea, la esencia, no sólo se transmiten físicamente por la ingestión, sino que existen momentos y lazos que son culminantes - como diría Van Gennep- tal como tradicionalmente se atribuye a los padrinos en el bautismo, donde el agua, los óleos y las palabras confieren al niño un nuevo estado. En la percepción sacramental, el bautismo es ritualmente un nuevo nacimiento que cambia la situación del que lo recibe ${ }^{75}$. Entre otros muchos, podríamos tomar como ejemplo el caso de Ibiza, donde el padrino, cuando vuelve de acristianar a su ahijado lo entrega a la madre con las siguientes palabras: "Aquí teniu es vostro infant, mos l'enduguerem moro i el tornem cristià" "Aquí tenéis a vuestro hijo; me lo llevé moro y os lo devuelvo cristiano"). Esta expresión hasta no hace muchos años estaba extendida por casi toda la geografía españo-

75 Maria-Àngels RoQue, "El aceite y el vino en los rituales de las sociedades mediterráneas", F. Xavier MEDINA (ed.), La alimentación mediterránea. Historia, cultura, nutrición (Barcelona: Icaria, 1996). Cf. también Maria-Àngels RoQuE, "La cigogne et la chouette en Castille", Ethnologie française, n. ${ }^{\circ} 4$ (1989). 
la. Esta conjunción (el bautismo) es un momento de tránsito, en que se pueden recibir también las cualidades y los defectos de los padrinos; por eso es una cuestión delicada escoger padrinos que sean lo suficientemente cabales ${ }^{76}$, como expone Macabich en sus notas costumbristas. Este autor, que, como sabemos, es sacerdote, no reniega de este hecho, como en el caso de la covada; sin embargo, exclama: "esto ha rayado casi en la superstición. Cuando un chico demuestra un genio irascible, comete alguna ligereza o se manifiesta despejado o de buena índole, los padrinos sirven de comparación y cargan con la gloria o con la infamia".

Amades cuenta también que de forma generalizada en Cataluña, pero sin precisar el lugar exacto, los ahijados asimilan las cualidades y virtudes de sus padrinos. Más concretamente, dice: "Hemos oído contar de muchachas que se han dado a la mala vida porque su madrina no tenía el honor en gran estiman. $Y$ añade un refrán que de nuevo tiene que ver con las entrañas: "Si el compare és fetge i la comare freixura, a qui s'ha d'assemblar la criatura?" ("Si el compadre [padrino] es hígado y la comadre [madrina] es bofe, ¿a quién se parecerá la criatura?).

\author{
MARIA-ÀNGELS ROQUE \\ Institut Català de la Mediterrània. Barcelona
}

A través del trabajo de campo en las Baleares y Pitiusas, se expone en el presente artículo que la covada ha existido en estas islas hasta fecha relativamente reciente, y que supone, primordialmente, un ritual de carácter jurídico en el cual el padre es socialmente reconocido como progenitor del recién nacido. Esta característica sociológica refuerza, por otro lado, los aspectos míticos y rituales que confieren a determinados elementos naturales las características anímicas constitutivas de la persona.

Based on her fieldwork in the Balearic islands, the author argues that the couvade has existed in them until recently, mainly as a jural rite by which a man is socially recognized as the father of a newborn. The social function of the custom reinforces the mythical and ritual aspects that bestow upon certain natural elements the capacity of constituting the personality of a human-being.

${ }^{76}$ Los padrinos son considerados como "vehículo de la gracia", y son llamados "padres de gracia". La buena suerte es la gracia. Cf. Julian PitT-Rivers y John G. Peristiany (eds.), Honor y Gracia (Madrid: Alianza Editorial, 1993). Antonio Cea (comunicación personal) me informó de que en Asturias existe el dicho: "Se lo pegó en la pila", también referido a las cualidades, tendencias, manías, etc., que los padrinos transmiten a sus ahijados a través del bautismo. 